\title{
Erratum to: Plasmonic properties of gold nanoparticles covered by silicon suboxide thin film
}

Evgeniy Baranov", Alexandr Zamchiy, Aleksey Safonov, Sergey Starinskiy and Sergey Khmel

Kutateladze Institute of Thermophysics SB RAS, 630090 Novosibirsk, Russia

Original article: EPJ Web of Conferences 159, 00003 (2017), DOI: 10.1051/epjconf/201715900003

In acknowledgements, there is an error in the number of the grant; "grant №16-10-10506" should be replaced by "grant №16-19-10506".

\footnotetext{
* Corresponding author: itpbaranov@gmail.com
} 